\title{
Empirical Research on the Efficiency of Shaanxi Technology Finance to Support Technological Innovation
}

\author{
Jin Huining \\ School of Humanities, Economics and Law \\ Northwestern Polytechnical University \\ Xi'an, China
}

\author{
Duan Jie \\ School of Humanities, Economics and Law \\ Northwestern Polytechnical University \\ Xi'an, China
}

\begin{abstract}
This paper studied the input-output efficiency of technology finance resources to technological innovation in some areas of China by DEA-Malmquist empirical method. Through comparative analysis, it is found that the average comprehensive efficiency of Shaanxi was 0.89 in the past decade, which is at a relatively backward level, and the scale efficiency value of Shaanxi is less than the pure technical efficiency value. It shows that Shaanxi has more advantages in technology than in scale. In the future development, it is necessary to continue to increase investment in technology finance resources. The main innovation of this paper is to analyze the support efficiency and existing problems of Shaanxi technology finance to technology innovation from the overvall perspective of technology finance resources, which can improve the deficiencies caused by the analysis of single technology finance resources.
\end{abstract}

Keywords—-technology finance; technological innovation; DEA; Malmquist

\section{INTRODUCTION}

After nearly 40 years of reform and development, China's economic strength has been significantly enhanced, the people's living standards have been continuously improved, the total GDP has made a qualitative leap, and the international status has become higher and higher. However, at present, China is still the largest developing country in the world, still facing problems and challenges such as unbalanced development, insufficient development quality, insufficient innovation capability. The level of science and technology and innovation capacity are still the main obstacles to economic development. Because of the risks of technological innovation, financing has become the biggest external bottleneck for technology innovation companies, and has become a major obstacle to building innovative country. Therefore, technological innovation has a growing demand for technology finance [1]. Only by attaching importance to technology finance, can we better accomplish the goal of building an innovative country.

In Shaanxi Province, due to its geographical location in the northwest inland and various factors, its overall economic

This research was sponsored by the Seed Fundation of Innovation and Creation for Graduate students in Northwestern Polytechnical University (ZZ2018215). development level and innovation capacity are not consistent with rich scientific and technological resources. Based on this background, this paper analyzes the problems existing in Shaanxi technology finance to support technological innovation.

Domestic and foreign scholars have carried out a lot of research on technology finance and technological innovation about the relationship, the problems in many provinces and cities, and the typical development model [2] [3]. Selecting indicators from many aspects to reflect the development of technology finance support for technological innovation, and providing rich policy advice from different perspectives to strengthen the support of technology finance for technological innovation [4]. These studies provide a certain theoretical basis for this paper, and provide a reference for the overall research ideas of this paper. However, the existing literature mainly focuses on the effect of financial investment, venture investment, capital market and other factors on technological innovation [5]. There are few studies on technology finance from the overall perspective of resources. Based on the relevant literature and the research content and methods of this paper, this article mainly from the overall perspective to analyzes the supporting of Shaanxi technology finance to technological innovation and existing problems.

\section{THEORETICAL BASIS}

Technology finance is an important part of the national financial system and technological innovation system, mainly referring to an industrial model combining science and technology with finance. Theoretical scholars believe that technology finance refers to a series of systematic and innovative arrangements for financial instruments, financial systems, financial policies and financial services that promote scientific and technological research and development, the transformation of scientific and technological achievements and the development of high-tech industries [6]. The technology enterprises and the financial system cooperate with each other to combine the two major productivity factors of technology resources and financial resources to promote technological innovation, provide scientific and technological innovation power, and accelerate the construction of innovative countries. 
Technological innovation refers to technologies and processes created or summarized by new theories, knowledge and experience, to improve production efficiency and service quality by improving the production environment, improving production methods and production processes, improving business models and the technical content of new products [7].

Technology finance and technological innovation are an inseparable group, technology finance plays a significant role in promoting technological innovation, and the need for technological innovation is the driving force for improving the technology financial system and policies [8].

\section{A. Intrinsic Demand}

Every innovation and every invention requires a lot of manpower and material resources. At every stage of technological innovation, enterprises may face the risk of innovation failure [9]. Without the support of technology finance, it is difficult for science and technology projects to proceed smoothly. Therefore, technological innovation has a strong internal demand for technology finance.

\section{B. External Support}

Technology finance provides financing support and a good research environment for technological innovation enterprises. In the early development of technological innovation enterprises, financial technology resources, technology loans and venture capital investment provide financial support for enterprises to help solve financing problems in the event of market failure. With the continuous development of enterprise production, these three kinds of technology financial resources gradually withdraw from the stage, the technology capital market will play an important role in concentrating the idle funds of the society, investing in high-tech industries, and promoting the development of technological innovation enterprises. In addition, the development of technological innovation enterprises often has high risks, such as technical risks and economic risks. These risks will bring great obstacles to the development of technology enterprises, which the enterprises themselves cannot bear. Under the joint action of financial intermediaries and financial markets, technology finance resources, such as technology guarantees and technology insurance, can effectively help technological innovation enterprises to diversify risks, transfer risks, avoid risk losses, and ensure the normal development.

\section{EMPIRICAL ANALYSIS}

\section{A. Indicator Selection}

1) Index selection of technology finance input. The amount of fiscal technology expenditure can directly represent the investment in financial technology resources, the balance of local and foreign currency loans indirectly represents the investment in technology loans, the total amount of the venture capital investment management capital represents the support of venture capital investment for technological innovation.

2) Index selection of technology innovation. The number of patent grants directly reflects the output level of the basic research stage, the size of the technology market transaction volume reflects the market efficiency of the transformation of technological innovation achievements, and the sales revenue of new products of industrial enterprises above designated size expresses the economic benefits of technological innovation products.

3) Sample selection. According to the availability of data, there are 13 samples as the evaluation units, including whole country, Beijing, Tianjin, Shanghai, Jiangsu, Zhejiang, Anhui, Shandong, Hubei, Hunan, Guangdong, Sichuan and Shaanxi. According to the panel data of 13 samples from 2007 to 2016, this paper studied the efficiency of technology finance resources to technological innovation by the output-orientated variable returns to scale model (VRS model) on using DEAP2.1 software. Due to the time lag of the impact of technology finance investment on the technology innovation output, the output data is delayed by one year in the empirical study, so there are 9 years from 2007 to 2016.

\section{B. Empirical Results}

TABLE I. THE AVERAGE EFFICIENCY OF EVERY REGION

\begin{tabular}{|c|c|c|c|}
\hline region & crste & vrste & scale \\
\hline whole country & 0.771 & 1.000 & 0.771 \\
\hline Beijing & 1.000 & 1.000 & 1.000 \\
\hline Tianjin & 0.924 & 0.973 & 0.944 \\
\hline Shanghai & 0.801 & 0.852 & 0.945 \\
\hline Jiangsu & 1.000 & 1.000 & 1.000 \\
\hline Zhejiang & 0.999 & 1.000 & 0.999 \\
\hline Anhui & 0.849 & 0.979 & 0.862 \\
\hline Shandong & 0.994 & 1.000 & 0.994 \\
\hline Hubei & 0.953 & 0.985 & 0.966 \\
\hline Hunan & 0.958 & 1.000 & 0.958 \\
\hline Guangdong & 0.900 & 0.949 & 0.947 \\
\hline Sichuan & 0.941 & 0.976 & 0.963 \\
\hline Shaanxi & 0.890 & 1.000 & 0.890 \\
\hline
\end{tabular}

By observing the average efficiency of technology finance supporting technological innovation in the past decade, it is found that the average comprehensive efficiency of Beijing and Jiangsu is the highest, reaching 1 , and the average comprehensive efficiency of Zhejiang and Shandong is close to 1. The support of technology financial resources for technology innovation is very significant in these four regions. The average comprehensive efficiency of Tianjin, Hubei, Hunan, Guangdong and Sichuan is higher than 0.9. The support of technology financial resources for technological innovation activities is relatively strong, but it still differs from the production front surface by a distance. The average comprehensive efficiency of Shaanxi Province is 0.89 , which is at a relatively backward level, and the scale efficiency value is less than the pure technical efficiency value, which indicates that Shaanxi has more advantages in technology than the scale. In the future development, it is necessary to continue to increase investment in technology financial resources. 
TABLE II. MALMQUIST INDEX AVERAGES OF EVERY REGION

\begin{tabular}{|c|c|c|c|c|c|}
\hline region & effch & techch & pech & sech & tfpch \\
\hline whole country & 0.996 & 1.013 & 1.000 & 0.996 & 1.008 \\
\hline Beijing & 0.980 & 1.000 & 1.000 & 0.980 & 0.980 \\
\hline Tianjin & 0.994 & 0.980 & 1.000 & 0.994 & 0.974 \\
\hline Shanghai & 0.975 & 1.020 & 1.000 & 0.975 & 0.994 \\
\hline Jiangsu & 1.000 & 1.036 & 1.000 & 1.000 & 1.036 \\
\hline Zhejiang & 1.000 & 1.027 & 1.000 & 1.000 & 1.027 \\
\hline Anhui & 1.065 & 1.008 & 1.014 & 1.050 & 1.074 \\
\hline Shandong & 1.000 & 1.000 & 1.000 & 1.000 & 1.000 \\
\hline Hubei & 1.000 & 1.018 & 1.000 & 1.000 & 1.018 \\
\hline Hunan & 1.013 & 1.038 & 1.000 & 1.013 & 1.051 \\
\hline Guangdong & 1.000 & 1.027 & 1.000 & 1.000 & 1.027 \\
\hline Sichuan & 0.972 & 1.097 & 0.995 & 0.977 & 1.066 \\
\hline Shaanxi & 1.003 & 1.025 & 1.000 & 1.003 & 1.028 \\
\hline
\end{tabular}

In the above table, tfpch is the total factor productivity index (TFP index), which is the Malmquist index, and tfpch is greater than 1 , indicating that the efficiency of the support of technology financial investment in technological innovation output is increased. If it is less than 1, it means that the efficiency of the support of technology financial investment in technological innovation output is decreased. Techch is a technology change index that measures the impact of technological advancement and technological innovation on technological innovation output. Pech is a pure technical efficiency index, which indicates the extent to which technology finance input contributes to technological innovation output under the constant economies of scale. Sech is a scale efficiency index, indicating that due to changes in scale, the impact of technology finance investment on technological innovation output, if this value is greater than 1 , indicating that scale changes have a positive effect on technological innovation output, if the value is less than 1 , it indicates scale changes have an inhibitory effect on technological innovation output, and if the value is equal to 1 , it means that the scale changes have no effect on technological innovation output.

According to the empirical results obtained by the DEAMalmquist method, from 2007 to 2016, the total factor productivity index of China's technology finance to support technological innovation is 1.008, which indicates that the support efficiency of technology finance investment in technology innovation output is rising. From a regional perspective, the total factor productivity index of Beijing, Tianjin, and Shanghai is less than 1 , which indicates that the support efficiency of technology finance investment in technology innovation output in these three regions is declining, probably because the development environment of technology finance in these three regions has already relatively mature, the positive impact of the technology financial resources investment on the technology innovation output has diminished marginal utility. In the later development, it should properly control the technology finance investment, and continuously innovate the support channels and support mechanisms for technology finance to promote the development of technology innovation.

In addition to Beijing, Tianjin and Shanghai, the support efficiency of technology finance investment on the technology innovation output in other regions is greater than 1 , and higher than the national average, the development of technology finance is better. The analysis found that the total factor productivity index of Jiangsu, Zhejiang, Hubei and Guangdong provinces is greater than 1 , which is a significant positive impact of technological progress on technological innovation, especially in Jiangsu Province, the technology change index reached 1.036, which is in a leading position; Under the dual effects of scale efficiency improvement and technological progress, Anhui and Hunan have higher total factor productivity index. Although Sichuan's scale efficiency has declined, its technological progress has been obvious, and the total factor productivity index has even surpassed some eastern countries. The technology financial environment in Shaanxi Province is also constantly improving, and both scale efficiency and technological progress have been significantly improved. As an important province in the west, Shaanxi and Sichuan, with the implementation of the great western development strategy and the construction of the "One Belt One Road” economic belt, the government attaches more and more importance to the output of technological innovation, and has gradually put the improvement of technology financial environment into practice, the role of technology finance investment in the promotion of scientific and technological innovation output has been continuously enhanced, and the support efficiency has been significantly improved in the last decade.

\section{SUMMARY}

The investment in technology financial resources in Shaanxi is increasing, but the overall investment intensity has not yet reached a high level. Fiscal science and technology expenditures account for a lower proportion of general budget expenditures. The level of science and technology loans is insufficient to meet the production needs of enterprises, and the number of venture capital investment institutions and management capital is in a lower position in China.

From the empirical results of DEA, the average comprehensive efficiency of Shaanxi is at a relatively backward level, and its scale efficiency value is less than the pure technical efficiency value, which indicates that Shaanxi Province has more advantages in technology but in the scale. In the future development, it should work harder to continue to increase investment in technology financial resources.

From the empirical results of Malmquist, the technology financial environment in Shaanxi Province is also constantly improving, and both scale efficiency and technological progress have been significantly improved. With the implementation of the great western development strategy and the construction of the "One Belt One Road" economic belt, Shaanxi government pay more and more attention to technological innovation output, and has gradually put the improvement of technology financial environment into practice, the promotion of technology finance investment in 
technological innovation output has been enhanced, and the support efficiency has been improved.

\section{ACKNOWLEDGMENT}

This research was sponsored by the Seed Fundation of Innovation and Creation for Graduate students in Northwestern Polytechnical University(ZZ2018215).

\section{REFERENCES}

[1] Era D N, Kersting E K, Geneviève V. Firm Productivity,Innovation and Financial Development[J]. Social Science Electronic Publishing, 2012, 79(10/49):422-449.

[2] Po-Hsuan Hsu, Xuan Tian, Yan Xu. Financial Development and Innovation:Cross-country Evidence is $[\mathrm{J}]$. Journal of Financial Economics, 2014, 112(1):116-135.
[3] Geronikolaou G, Papachristou G. Venture Capital and Innovation in Europe[J]. Modern Economy, 2012, 3(4):1-7.

[4] Zhao Zhiyun. Leading the Supply-side Structural Reform with Technological Innovation[J]. China Soft Science, 2016(9):1-6.(In Chinese).

[5] Zheng Qiang. The Impact of Technological Innovation on New Urbanization--An Empirical Analysis Based on Panel Threshold Model[J]. Urban Problems, 2017(6):25-35. (In Chinese).

[6] He Dan, Yan Xin. An Empirical Analysis of the Efficiency of Financial Support for Technological Innovation[J]. Statistics \& Decision, 2017(10):166-168.

[7] Li Juncheng, Ma Jing. R\&D funding and technological innovation from the financing environmental perspective[J]. Forum on Science and Technology in China, 2017(2):135-142. (In Chinese).

[8] Zhao Lixia, Tan Chao. The Empirical Study on the Dynamic Mechanism of the Influence of Fiscal Policies on Technological Innovation[J]. Scientific Management Research, 2017(1):99-102. (In Chinese).

[9] Qi Yong, Guo Yi. An Empirical Research on the Interactive Development of Jiangsu's Sci-tech Finance and Technolonical Innovation [J]. Science \& Technology Progress and Policy, 2017(9):1-9. (In Chinese). 